\title{
A NEW TOOL TO IMPROVE Quality Product - Sign Language
}

\author{
BOCA, G.D.
}

Abstract: In recent years there have been an increasing demand for more comfort concerning noise. It is here for more necessary that the manufacturers of machinery include aspects of noise control in the design control. As we can know gears-quality depend not only of manufactured tolerance quality, material, but also in the last few years a lot of research investigations show that the vibration and acoustic problem can also influence the gear quality. Because the trend is new it is a good opportunity to give a more carefully attention to this problem, as a matter of fact that noise problem influence not only the environment but also can help to predicted the failure of gears. Manufacturing Quality is very important, so the study of wear of gear contact is becoming one of the emerging areas in gear technology. Until now a lot of investigations found different solutions for the improvement of quality, but the problem of low design solution remaining an open field. This paper aims to launch new directions of research in theoretical and experimental modeling graphic for planetary gears, as a method of static and dynamic investigation used to improve quality and reliability.

Key words: quality, sound, improvement, passive sources, active sources
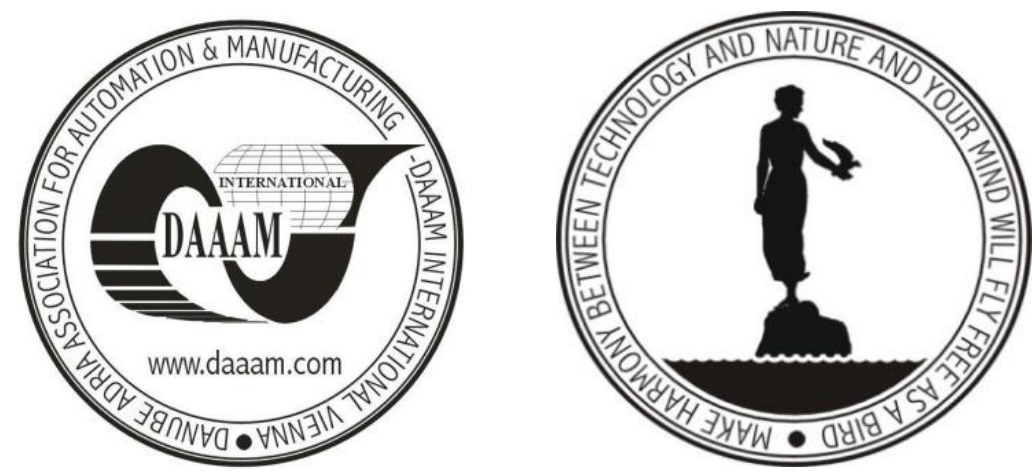

Authors' data: Assoc.Prof. Dipl-Ing. Dr. Boca, G[ratiela] D[ana]; *North University of Baia Mare, 76,Victoriei 430083 Baia Mare, Romania, bocagratiela@yahoo.com,

This Publication has to be referred as: Boca, G[ratiela] (2010). A new tool to improve quality product - sign language, Chapter 68 in DAAAM International Scientific Book 2010, pp. 787-800, B. Katalinic (Ed.), Published by DAAAM International, ISBN 978-3-901509-74-2, ISSN 1726-9687, Vienna, Austria

DOI: $10.2507 /$ daaam.scibook.2010.68 


\section{Introduction}

The topic of research was to find an answer to the question: Which is the connection between noise and quality?

To identify the connection, I start from the effect(noise) to the cause(wear) using the fish-bone diagram for planetary gears and draw up the scheme from Fig.1.

The analytical method for the input and output points from the gears contact zone presents small values for the wear speed, which encourages my investigation to other factors which were not taken into consideration.

The connection between wear and sounds for planetary gears can be established if one can understand the signals which can prevent the future failures or some internal damage problems of the system.

In conclusion sounds can be used as a tool to improve quality and define internal problems.

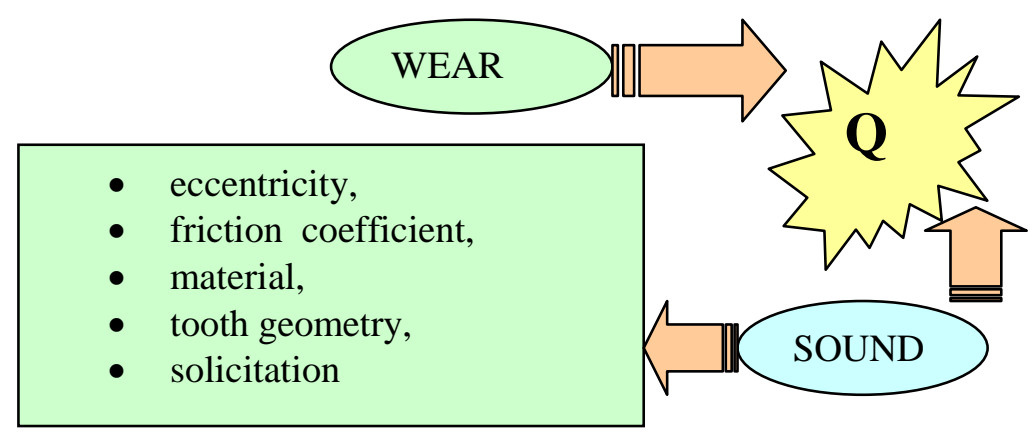

Fig. 1. Factors which can influence quality for planetary gears

In time, sound becomes noise, the first sign of wear which modifies the life cycle of the product. For that reason it is not necessary to wait until the product is finished and then determine the causes of its flaws.

We can improve the quality and reliability from the first design stage of the product, using a new method which can reduce both the costs of maintenance and the manufacturing time.

Acoustic vibration is a parameter considered as a very secure tool used in controlling and predicting planetary gears behavior and health.

Sound can also be used to diagnose all the modifications at different stages of production, through the entire life cycle, to discover and improve the system reliability and determine how sound can prevent system problems.

For that reason, sound can be used as a tool to define the quality and proper functioning of a product.

The research topic was to determine the mechanism of excitation, the internal and external sounds sources, and the frequency values which can give the first signal of wear for future damage.

The mathematical model for planetary gears using FEM method determines the program solutions and identifies the first signals of wear.

The next step was to present the transformation of sound signals into vibration over time, as a result of the health communication of the system. 


\section{Research method}

The planetary gear quality is directly influenced by variation of sounds and vibrations between maximum and minimum values; in turn these factors are influenced by various generating noise sources.

The study of these factors will allow us to analyze their influence on planetary gear behavior. After identification of sounds sources, the connection between the planetary gears reliability and the appearance of the wear was done in Fig.2.

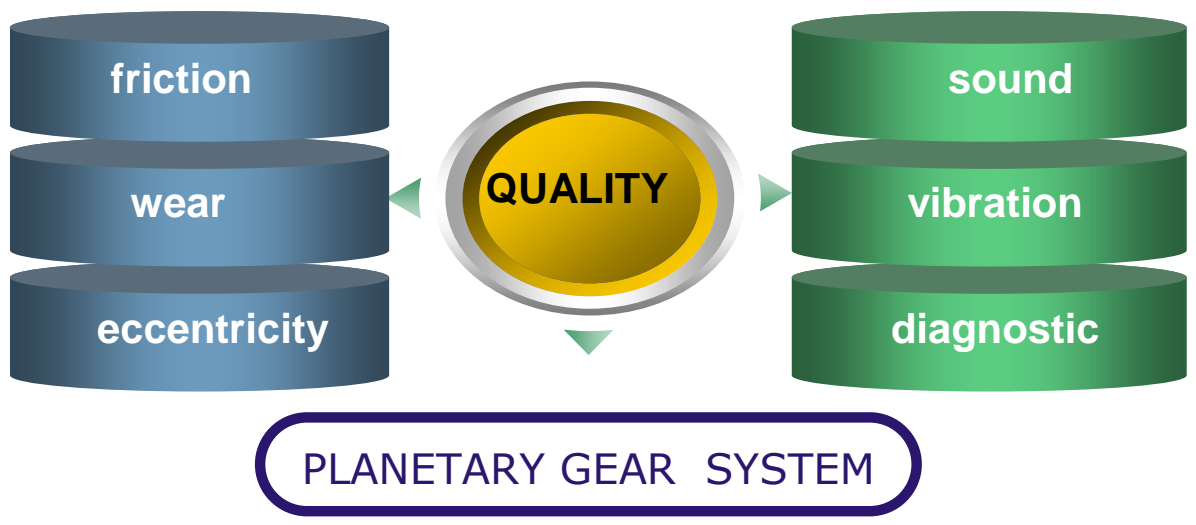

Fig. 2. Factors which can generate the noise for a planetary gear system

The topic of this chapter it is to present a solution which can improve quality if we are following idea: Unlike people who have verbal skills, machines use "sign language" to communicate what hurts or what has invaded their system

The planetary gear quality it is directly influenced by variation of sounds and vibrations between maximum and minimum values, in turn these factors are influenced by various generating noise sources.

The study of these factors will allowed to analyze their influence on planetary gear behavior. The investigation covered the following aspects for two constructive versions of planetary gears with rigid and floating solar gear:

- the sources of excitation for planetary gears;

- the sources which generate sounds;

- the vibration and acoustic influence upon the proper functioning of planetary gears;

- the specific frequencies in the vibration diagnosis for different types of solar gear assembly of solar fix -fix, fix-free, free-free.

Depending on the source - the source of air (the working environment), the source of liquid (lubrication), the source material (structural composition, housing, type of material) - planetary gears have a unique approach as to construction.

Keeping this approach for mechanical planetary elements connected in series, I identify the sound sources obtaining the path of sound transmission and power transmission of noise and vibration which and influence the system's reliability.

Taking into consideration the planetary gears as a mechanical system with all the components in series connection, each component can influence the entire reliability and quality system. 
The source generator of sounds for planetary gears can be classified taking into consideration the nature of the source:

air source - air-pocketing, because of the air between the teeth;

- material - structure - source - depends on the material and geometrical characteristics of the teeth;

- liquid source - considering the oil used for lubrication, both from the floating planetary gear as a new solution and the bearings from the rigid solution.

According to acoustic vibrations I established two types of noise generating sources: active sources and passive sources, which in turn may promote different forms of dissipation of the sounds for different frequencies.

These sources can be (Fig.3):

- active: stift, carrier, support-satellites, oil lubricant, inner with internal tooth;

- passive: satellites, solar gear, bearings, ax tree.

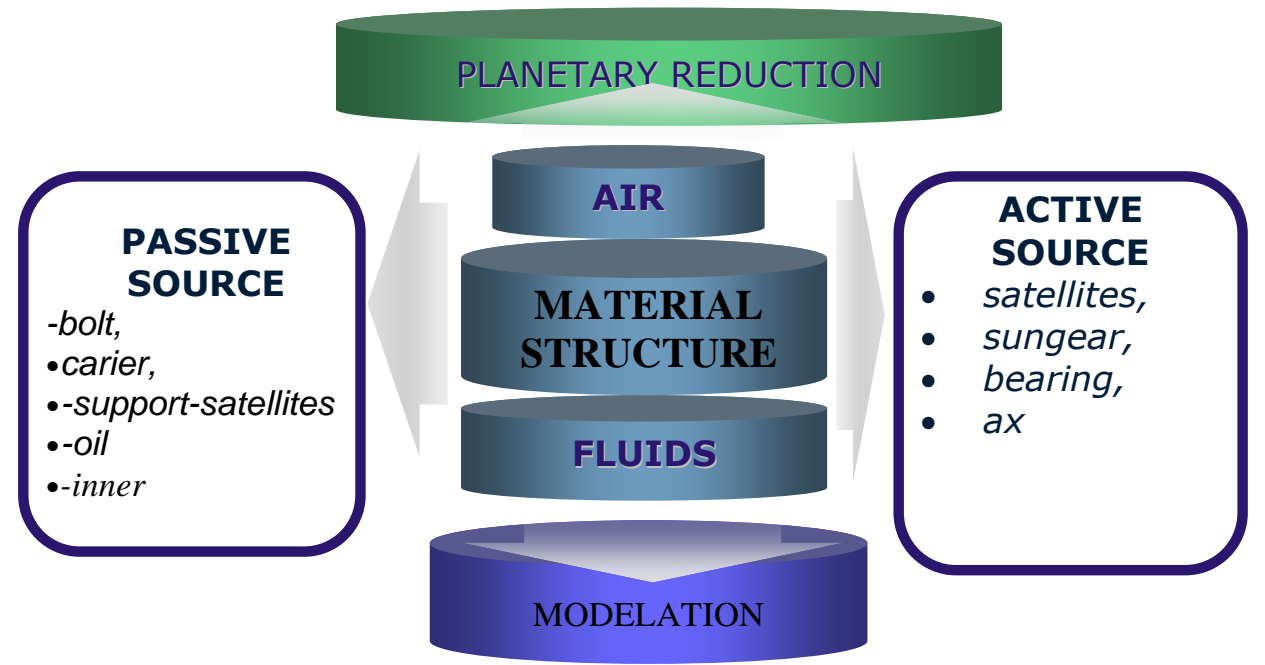

Fig. 3. Planetary gear with active and passive sources

\section{Experimental research using pulse program}

In this chapter the research activity was concentrated on experimental research to obtain values and experimental data for both constructive versions of planetary gears. The paper presents the experimental research for planetary gears with rigid and floating solar gear, a comparison of results obtained using different methods: experimental and virtual simulation.

I proposed for that reason the modeling method as a solution which can improve quality by making new products to low design frequency from the design stage, without being required to determine the causes of failures.

Engineering perspectives on life and reliability of planetary gears show that the vital part is the design stage followed by development, selection and analysis - the method which can improve quality system because not all of them can give solutions for the entire system or for a specific component.

In the laboratory from the North University of Baia Mare, I did the experimental research on a stand with an open circuit. 
The diagnostic was realized with a Machine Diagnostics Brüel\&Kjær TOOLBOX TYPE 9727 Program PULSE which captures direct influence of the sounds and frequency and transforms the sound into image.

The investigation was done for different $\mathrm{rpm}=500 \mathrm{rot} / \mathrm{min}, 1100 \mathrm{rot} / \mathrm{min}, 1200$ $\mathrm{rot} / \mathrm{min}$ and $1800 \mathrm{rot} / \mathrm{min}$, and I discovered the most common frequency values which give the significant sound signals for different steps: I, II, III, IV with a gearbox speed CV (Fig.4.).

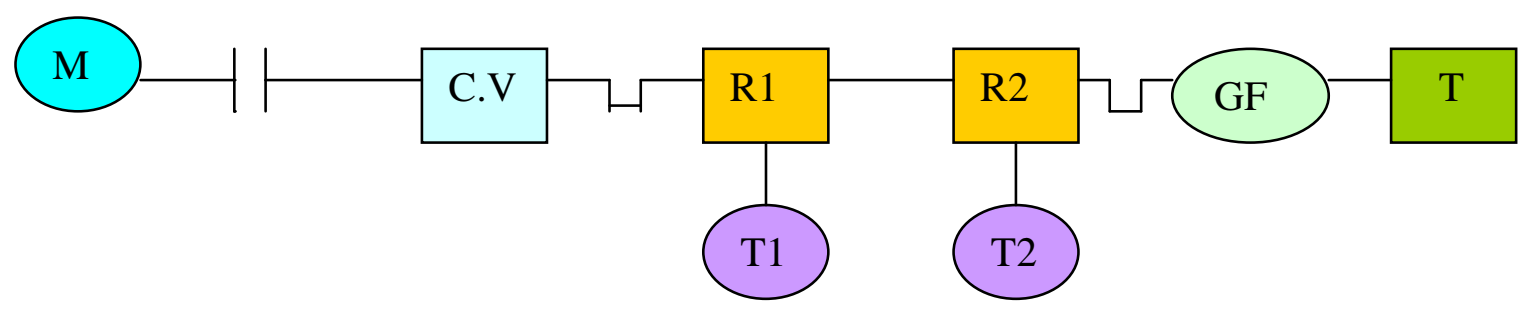

Fig. 4. The stand with open circuit $\mathrm{M}_{\mathrm{E}}$-electrical engine with alternativ curent, $\mathrm{CV}$-speed gearbox with IV steps, $\mathrm{C}_{1^{-}}$ambreiaj cu un disc, $\mathrm{R}_{1}$-rigide planetary reduction, $\mathrm{R}_{2}$-planetary gear system, G-tahogenerator, GF-generator, T-tranceduser

To define the influence of sound sources the transducers were fixed on the axial and radial part of the planetary gear to identify the influence of the sounds from both coordinates $\mathrm{x}$ and $\mathrm{y}$ with the Bruel \& Kjǽr PULSE program (Fig.5).

With the transducers montage on the planetary gear reduction box carrier in radial and axial position I investigated the influence of acoustic sound power and determined the important frequency which confirms the good quality of manufacture and the presence of some problems and damage in time.

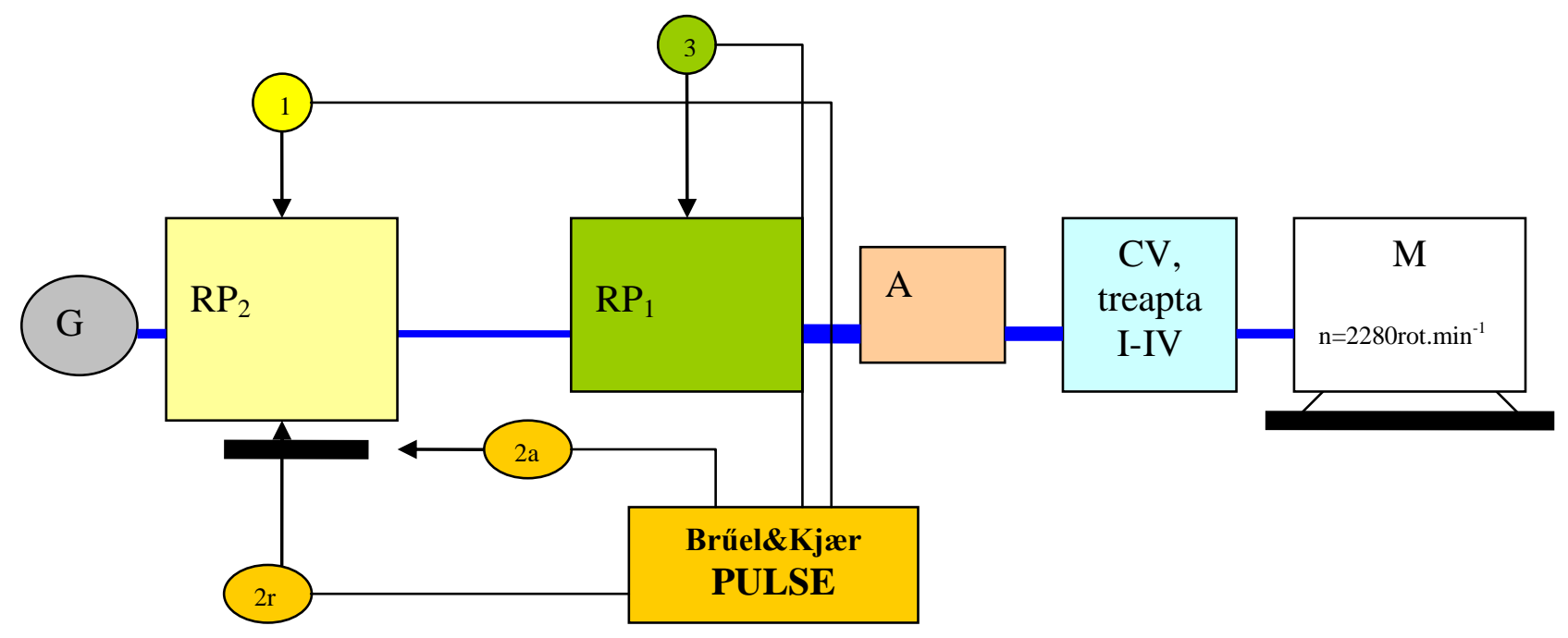

Fig.5. The schematic stand for vibroacustic measurements for planetary gear system

Using the spectrum analyze, I studied and interpreted the experimental data and identified the input forces, the structure tonality which can inoculate maximum and minimum tonality. 
Using harmonic analysis, the interpretation of statistical results presents the appearance of the primary and second sound.

The important frequency which confirms the presence of the first signal of sound and vibration was $20 \mathrm{~Hz}$ and $25 \mathrm{~Hz}$. for different values of speed and rpm values of planetary gears, both constructive types.

The method gives only solutions for the entire planetary gear and not to specific mechanisms, bodies in motion or forces which may be listed (Fig.6).

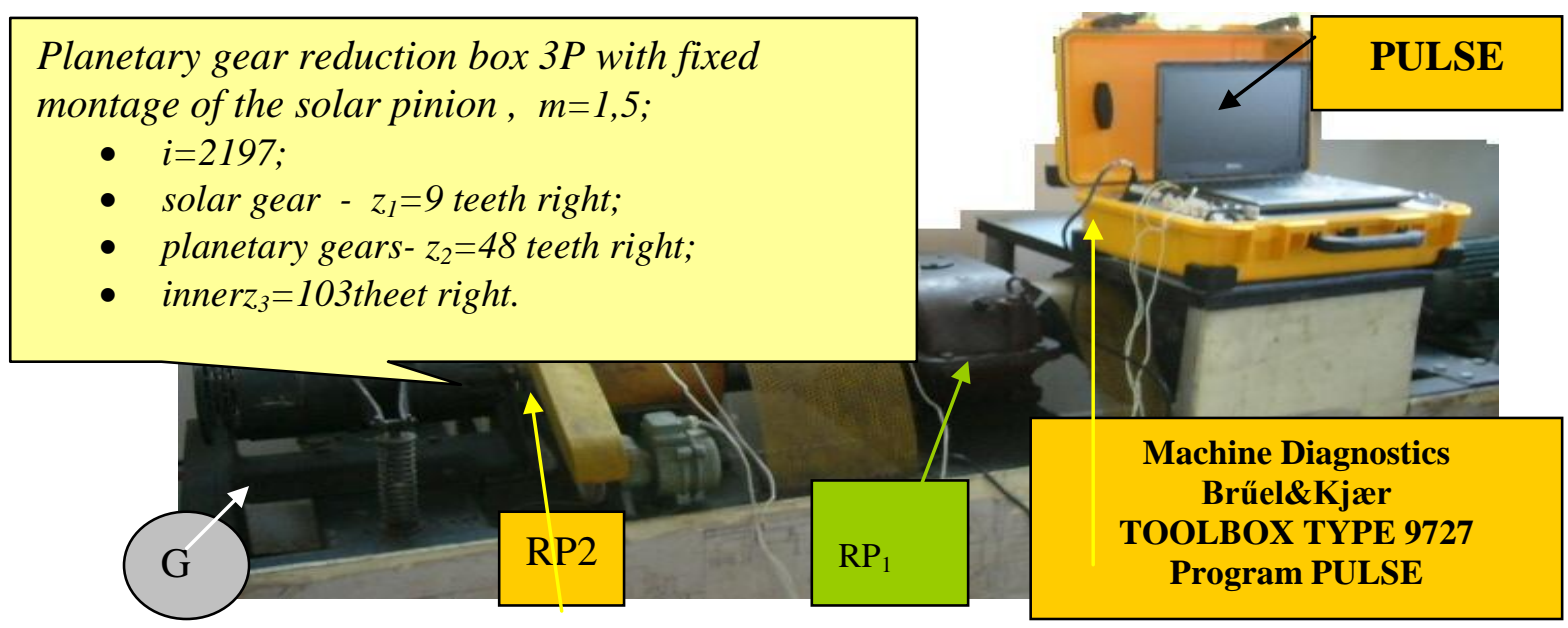

Fig. 6. Scheme stand for measurements performed acoustic motions for planetary reduction gear box RP2 with fixed solar pinion

The results obtained by using a normal tool for the identification of the quality characteristic for planetary gears present the experimental range of frequencies and acoustic pressure level for the planetary reduction version with fixed mounting solar gear for the idle and load running. The statistics show that:

- the data obtained by means of the experimental method using a stand with open circuit and PULSE program present the peaks of maximum frequency for $\mathrm{f}=50 \mathrm{~Hz}$ $100 \mathrm{~Hz}$;

- the experimental data obtained for planetary gears with fixed solar gear present an acoustic pressure situated by measurement and control on the curve Cz65-Cz75;

- the frequency noise characteristic for planetary reduction with floating solar gear is $\mathrm{f}=96 \mathrm{~Hz}-103 \mathrm{~Hz}$ and acoustic pressure placed on curves $\mathrm{Cz} 60, \mathrm{Cz} 70$. for idle and load running measurements.

The quality indicators help and give an interpretation for the planetary gear system and confirm again the results of quality and reliability improvement, the planetary gear noise decreases by $5 \mathrm{~dB}$ in the operation to empty and load planetary assembly with floating solar gear.

The experimental method shows that the optimal solution is the new constructive version of planetary gears with floating solar gear. The authors of this solution suggest the improvement of quality by using sound as a tool; this has to be verified using another method as well, the FEM solution which can improve the quality of products from the first stage of design and reduce the quality costs. This represents a method which can bring a green tech wind in industrial manufacture and 
create the possibility to use the same matrix data and model for the product and obtain quality from the design faze.

The challenge was to identify the differences between the experimental methods and the virtual method for both constructive versions of planetary gears.

\section{Model simulation to improve quality}

This paper aims to launch new directions of research in theoretical and experimental modeling graphic for planetary gears, as a method of static and dynamic investigation used to improve quality and reliability.

There are various methods for the diagnosis of planetary gears but not all are suitable worldwide.

Based on data obtained using the theoretical method and the experimental method used to capture the planetary gear sounds, results will be compared with the solutions obtained by using the virtual simulation of the product.

The model for planetary gears was done in the laboratories from IMW Clausthal, Germany using ANSYS program, and TOSCA program to optimize some program solutions and improve the quality of the product.

The method permits us to study the dynamic analysis for planetary gears using modal, transient and harmonic analyses, and identifying the frequency values as program solutions for different deformation and vibration phenomena for planetary gears.

The program in comparison with the experimental method gives the possibility to study each component of the entire system separately, to undertake a thorough investigation, to identify which are the weak points, and to find some solutions.

The mathematical model using modal analysis gives the opportunity to study the planetary gear as a system and identify the characteristics of the product and how the sound quality was improved for the new solution with floating solar gear (Fig.7).

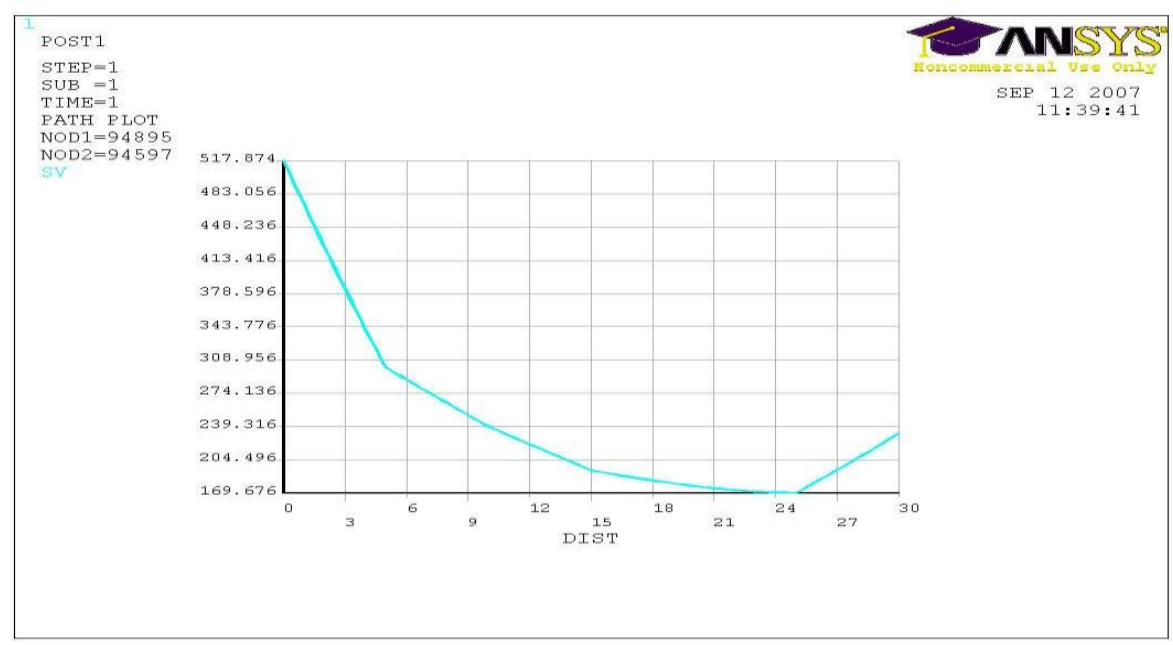

Fig. 7. Complete modal analyze for planetary gear system SV

Harmonic analysis applied to solar pinion brought information about the magnitude and phase frequency sounds that induce forces and vibration during operation planetary gear reduction SV, Fig.8. 


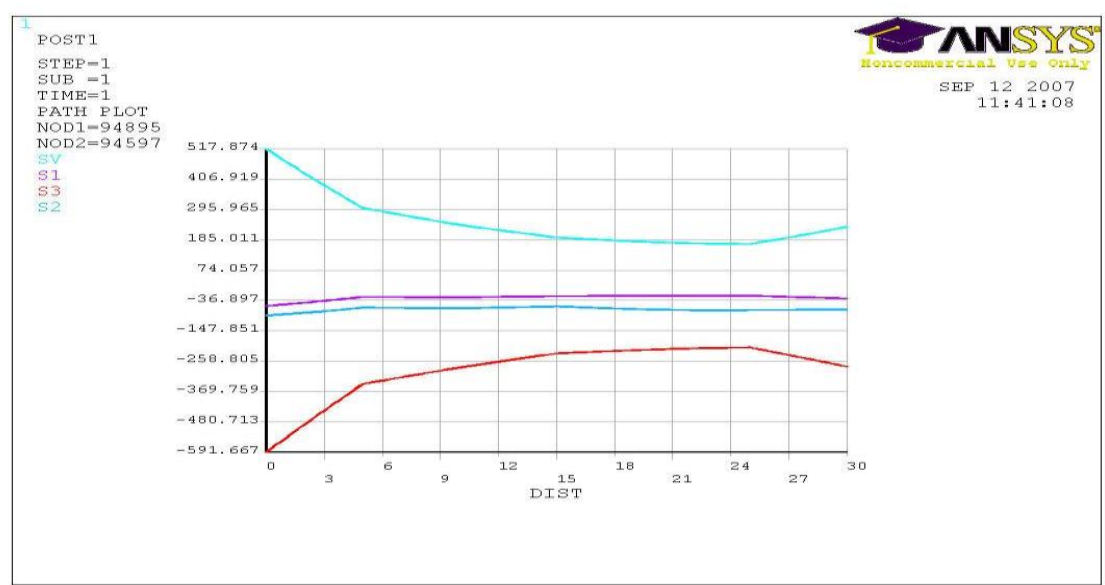

Fig. 8. Complete modal analysis for planetary gear systems SV, S1, S2, S3

The harmonic analysis for planetary gears with rigid solar gears presents the frequency $100 \mathrm{~Hz}$ as a principal value for vibration activity; the signal value generated by vibration for the same solution the experimental results present a Cz60Cz70 curve.

The results permit the visualization of the displacement on the axes $\mathrm{x}, \mathrm{y}, \mathrm{z}$, and total displacement USUM which show the influence of frequencies upon the amplitude answer to the displacement of the planetary gears (Fig.9)

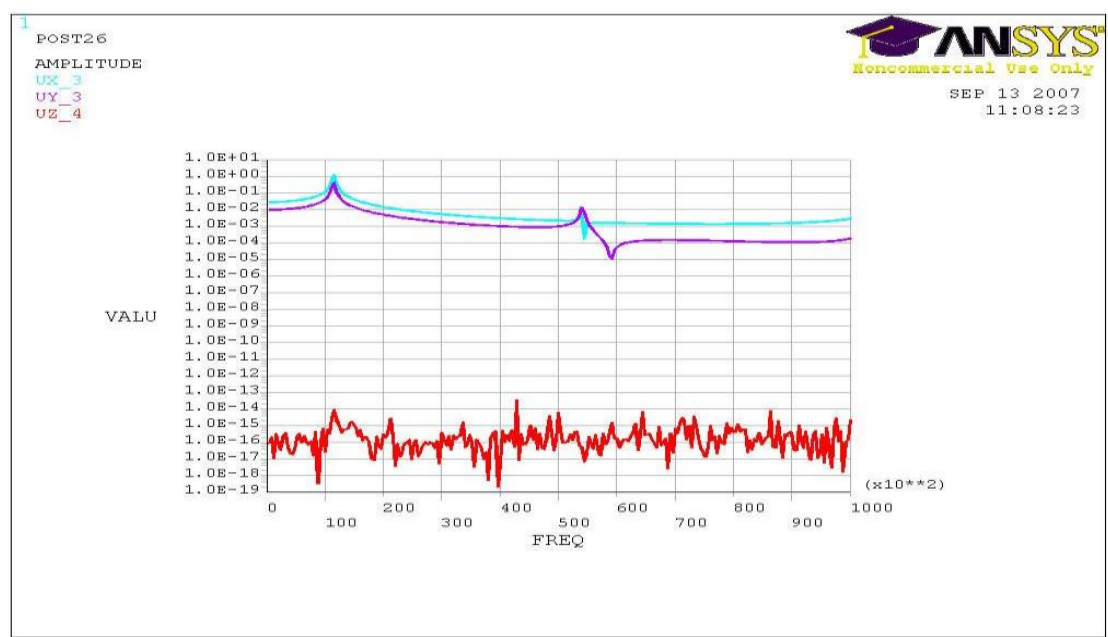

Fig. 9. Complete modal analysis USUM for planetary gear systems

Dynamic analyses for solar pinion permit the explanation of the phenomenon which are involved and induce the frequencies in the time function for planetary gear system.

The results present the solar gear as the most important part of planetary gears so a study using harmonic analysis applied to solar gears brought information about the magnitude and frequency sounds phase that induce forces and vibration during the operation of planetary gears.

The database of matrix model permit at this phase the variation of certain values for solar gears of different types of assembly fix-fix, free-free and free-fix, for 
each solution it is possible to establish and determine the frequencies for first strains and vibrations.

All the data can be kept and used to determine other solution which can improve the sound quality of the product.

The impulse force was calculated based on technical data provided by the manufacturing company producing values which allowed the investigation and study of the solar behavior pinion.

\section{Results}

In this paper I have presented experimental tests conducted by the author for the two variants of constructive planetary gears with floating and rigid solar gear.

The new version suggested, with free mounting of the solar gear, is based on mounting the wheels of the planetary system equalization with floating bearings which is more efficient because there is a load equalization for wheel planetary.

This system allows the gears, solar pinion, and planetary gears to be fitted with camps, which leads to the solutions of floating during the spur gearing.

The planet carrier is mounted on rolling bearings, floating encouraged of wheel assembly is done by planetary rolling oscillating bearings or with cage needles bearings. Improving the quality and reliability worldwide can be achieved by replacing old constructive versions (with the fixed antifriction mounted solar gear) with the new version proposed by the author (with free slide on the solar gear).

In the final stage the mounted solar gear is free, so all three wheels gearing with the planetary forces are equal, the reactions from the inside are equal, equalization indirectly created by the free installation of solar gear.

The rolling bearings libratory is a solution to avoid errors that can occur due to the assembly of solar gears against bending and can compensate for angular errors of alignment of shafts and housing. For this reason I consider that the new version is the best solution for our case study.

The solution for the floating montage for planetary gear was sustained once again because we already know that helical teeth mean a lot of noise because of the radial forces and also we can see that the displacement has the maxim value for the gear section of the solar pinion.

The experimental data obtained for the different planetary gears constructive solution were compared with the data obtained using the FEM method, virtual modeling and simulation and also with data obtained using tools to measure the quality characteristics.

The target of the study was to analyze how the behavior and transmission of vibrations arising from the actions fatigued on the planetary gear reduction box during operation.

The FEM method gives solutions using harmonic, transient usage of the information regarding the noise.

Each method has its contribution in achieving the quality of phase calculation to achieve a virtual product, and that is why research was conducted and planetary gear with a rigid solar gear reached a certain stage of the lifecycle. 


\section{Conclusion}

Studies done in our country and abroad have resulted in a general methodology for designing planetary gear reduction box reliability, so the problem must be addressed for each particular component of the planetary gears items related to the series connection.

Starting from the idea of connecting elements in series for planetary reduction box and the existence of a link between sound-vibrations-wear, I approached the study of the vibration phenomena and the effect of transmission of sound from all parts of planetary gear reduction box. Based on data collected from the producer company the review of cases of planetary gears failures and planetary occurrence and analysis of wear phenomena I discovered that the solar pinion is subjected to more frequent failures, for that reason I proposed to improve and increase the reliability of the pinion by implementation of solar with rigid fixation of wheel.

The tool - sound sign, used as a tool for timely reporting of potential failure of parts of the planetary gears provides rapid diagnosis without needing to dismantle the piece, and helps ensure a preventive maintenance.

The first comparison was between experimental methods: using stand and PULSE program and the standard experimental method for the determination of curve $\mathrm{Cz}$ considered as quality tool for planetary gears, the results of the comparison between methods is presented on Fig.10.

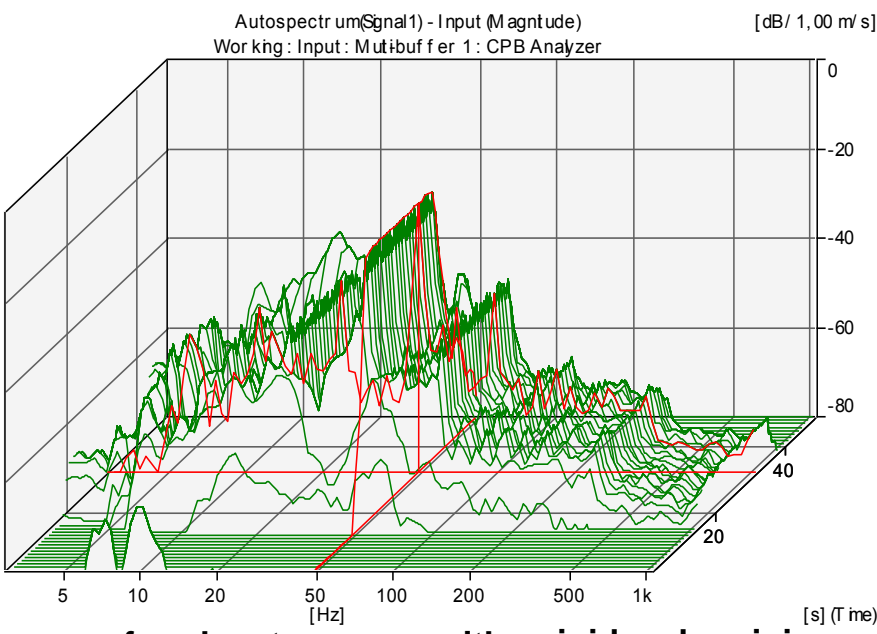

$\mathrm{Cz}$ curves for planetary gear with rigid solar pinion

Acoustic pressure level

[dB] 120

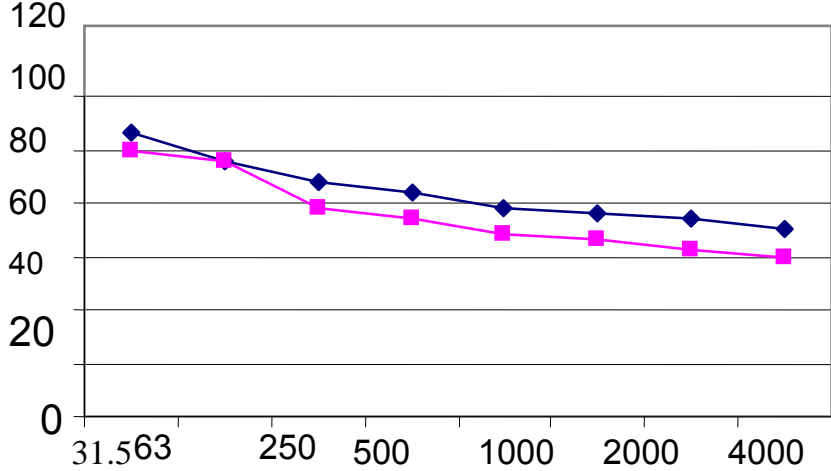

The maximum values peak for frequencies

$50 \mathrm{~Hz}, 100 \mathrm{~Hz}$.

Experimental dates obtain for planetary gear reduction box with fixed mounting of solar pinion

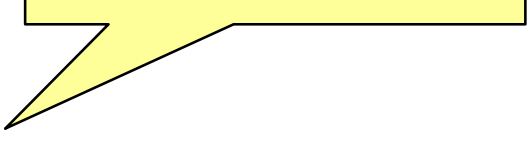

Characteristic frequancy for the planetary gear reduction box with fixed solar pinon mounting. Experimental dates give the solution

$\mathrm{Cz}$ 65-Cz 75

Frequency values $\mathrm{f}=100 \mathrm{~Hz}-163 \mathrm{~Hz}$

\section{Frequency $[\mathrm{Hz}]$}

Fig. 10. Final conclusions for planetary reduction gear box with fixed mounting of solar gear 
In our case for planetary gears with rigid solar gear the results are situated on the curves Cz60 Cz70 in comparison with Cz65- Cz75 curves for planetary gear with fixed mounted solar gear so in the standard limits.

The new constructive solution using floating solar gears, help quality by decreasing the pressure of the acoustic frequencies reducing frequencies values by $32 \%$.
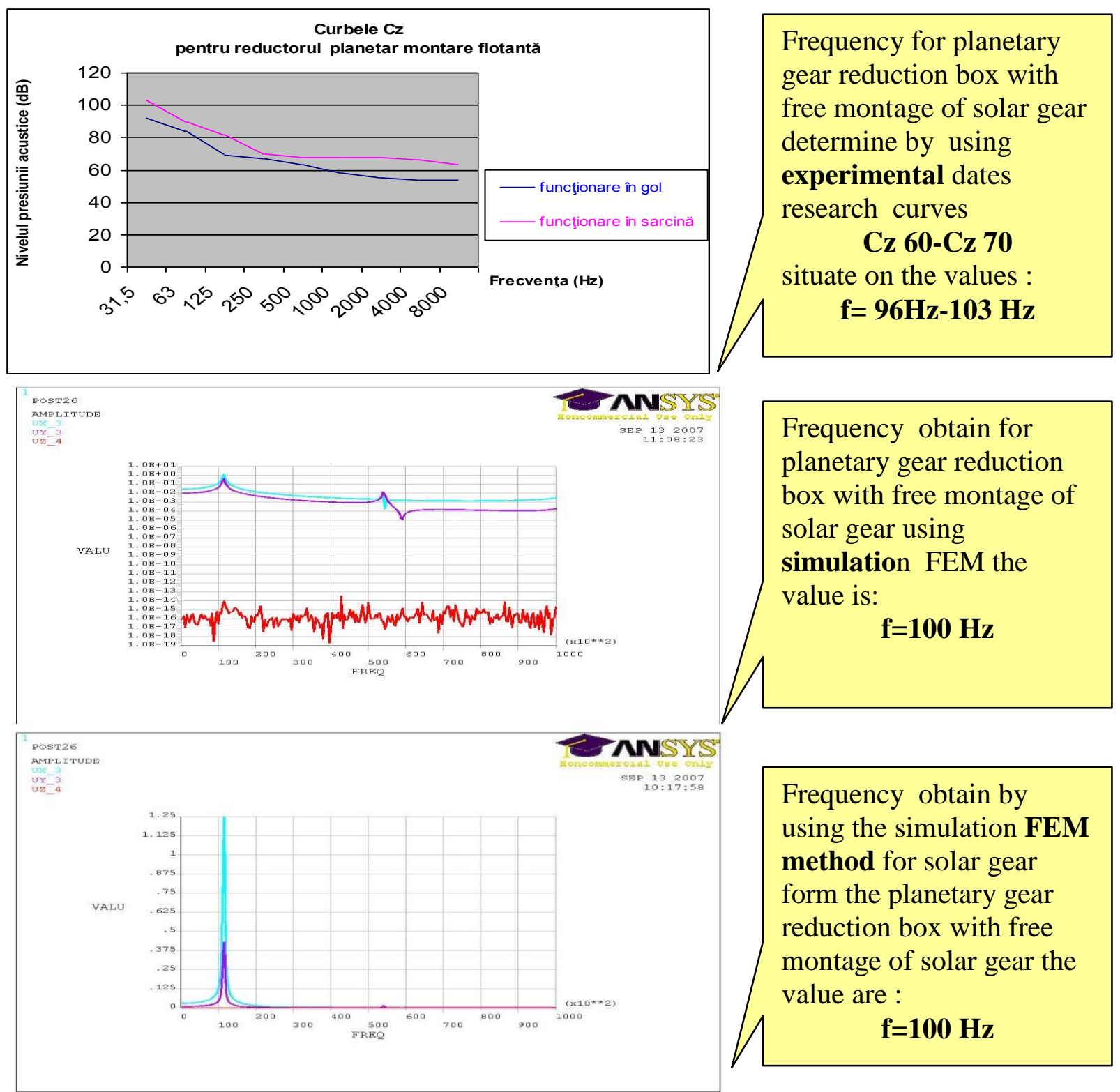

Fig. 11. Final conclusion for planetary reduction gear box with free montage of solar gear

Addressing the reliability problems showed that the solar pinion reliability is a challenge in addressing quality; the proposed solution for solar gear without the need of fixing with camps has to reduce sound during operation by $5 \mathrm{~dB}$.

The paper wants to promote sound as a tool which can be used to improve the quality of a product.

For that reason I made some parallels between different methods used in research work, analyzed them and choose the best. 


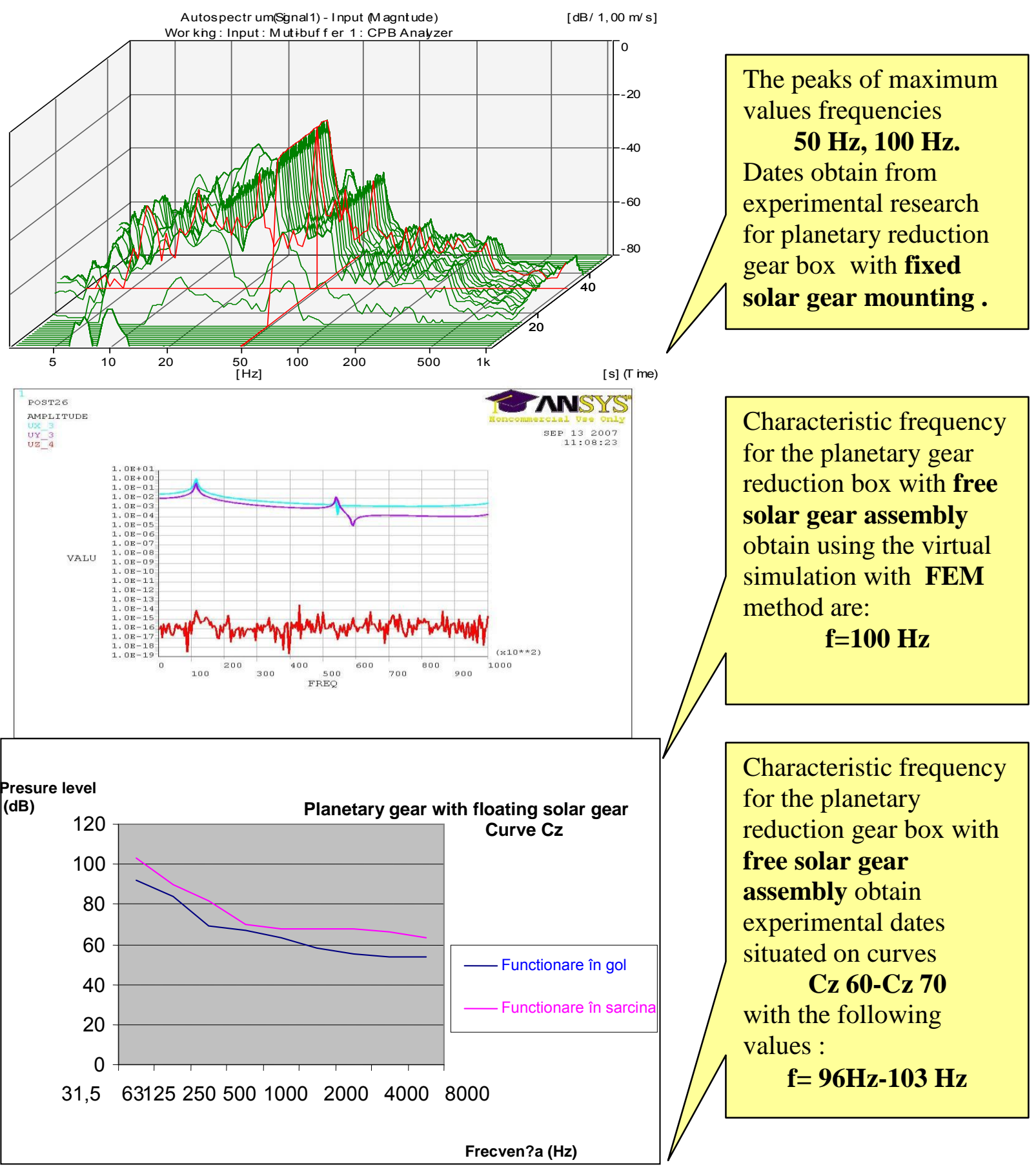

Fig. 12. Final conclusions for planetary reduction gear box with free and fixed solar gear montage

The second comparison was done between the standard experimental method used and the virtual method for the new constructive solution of planetary gears with floating solar gear, the final results present the same results regarding the quality improvement of the sound, so the method can be used to model the product.

As we can see, virtual simulation can help engineers to define and model quality from the design stage of creation of the product in our case for planetary gears with floating solar gear. 
In our case the author did also a comparison between both constructive versions for planetary gears and showed the benefice of each version with rigid and floating solar gear.

The final conclusion of the methods used in the research work and the results are presented in Fig.12, which shows the comparison between the experimental method and the virtual method for the entire system and separate for solar gear with floating gear.

The final results obtained through experimental research using the Pulse program have the mission to reveal significant frequencies and vibrations for planetary gears.

- the data obtained by the finite element method and experimental data obtained for the planetary reduction is free to mount an error of $\pm 3 \%$. (Fig.11, 12)

- the improvement of the quality planetary reduction by decreasing the frequency of generating noise and vibration. (Fig.12)

The topic of research was to use sound as tool to improve quality in this case for planetary gear with floating solar gear the results obtains are on the curves Cz60 Cz70 in comparison with Cz65- Cz75 curves for planetary gear with fixed mounted solar gear figure 12.

\section{Future research}

Using the data capture as matrix model for planetary gears and all the simulation elements studied in this chapter, we can distinguish several lines of research that can be followed in the future:

1. research work can be developed and can be continued to find new elements using virtual simulation and modeling the solar gear shape;

2. the paper provides also a new design using the finite element method used for the study of sign language and for simulation of wear phenomenon and vibration in particular for each component;

3. using quality and wear matrix the research work can be continued especially for carrier problems;

4. the model for solar pinion and the simulation results obtained for different montages of solar gears with rigid and floating version can be materialized by developing a design prescription aimed at choosing the appropriate version to obtain safety factors;

5. improving reliability and quality product and design to low frequencies products from the first stage of design.

\section{Reference}

Ai, X., Wilmer, M. Laurentz, D.(2005), Development of friction drive transmission, Journal of Ttribology, vol.127

Attia, M. H., (2005), Prediction of fretting fatigue behavior of metals using a fracture mechanism. Approach with special consideration to the contact problem, Journal of Tribology, ASME

Bartelmus, W.(2000), Mathematical Modeling of Gearbox Vibration for Fault Diagnosis, International Journal of COMADEM, Vol.3, no.4, 
Bartelmus, W. (2001), Mathematical Modeling and Computer Simulations as an Aid to Gearbox Diagnostics. Mechanical Systems and Signal Processing, Vol.15, nr5, s. 855- 871

Bartelmus, W, (2002), Computer-aided multistage gearbox diagnostic inference by computer simulation. Scientific Papers of the Institute of Mining of Wroclaw University of Technology. No.100, 2002, Wroclaw University of Technology, Poland

Broch, J.T.: Mechanical Vibration and Shock Measurement, Bruel / Kjaer, 1980

Dietz, P.(2005), Experimental determination of the tooth warring firmness, DIN 28919

Dietz, P.(2003), :Hub does not wave anything new to investigate, Institütfüraschinenwesen, Clausthal

Dietz, P.,(2006), Operating conditions and demonstration of bearing capacity of tooth and splined shafts connections

Dietz,P., Gummersbach, F.,(1999), Lärmarm, Konstruier XVIII, Systematische Zusammen- stellung maschinenakustischer Konsructionspiele, Dortmund

Dietz,P.,Schäfer, G., Wesolowski, K.(2003), InvoluteSplines-LoadabdWearBehavior, Institüte für Maschinenwessen, Clausthal

Dietz, P., Haje, D(2000), Development of low noise products computer aided guidance for the designer, International Conference Design 2000, Dubrovnick

Dietrich, G., Stahl, H.(2000), Matrizen und Determinanten in der Technik. VEB Verlag Leipzig

Frohlich, A.(2006), Investigations on the Reliability of FEA calculations on the microscopic scale, Journal of Mechanic

Kahraman, A. Yuksel, C, (2004), Dynamic Tooth Loads of planetary gears sets having tooth profile wear, Mechanism aand Machine Theory

Kapelevich, A.L.; Kleiss, R. (2002), Direct Gear Design for SPUR and Helical Involutes Gears Technology, September /October, p.29-35

Kolerus, J.(2000), Zustands Uberwachung von Maschinen, Kontact\&Studium

Kent, L.(2002), Ansys Tutorial. Relese 8.0 Mechanical and Aerospace Engineering, University of Texas

Kurovski, P. (2002), How to find errors in Finite Element Models, Machine Design

Lin, J., Parker, R.G. (2002), Planetary gears parametric instability caused by mesh stiffness variation, Academic Press

Linke, H., Trempler, U. (2005), Analyzes on the stress of teething planetary gears, Technishe Universitat Munchen

Susmel, L.,Lazzarin, P.(2001), A bi Parametric Wohler curve for high cycle multiaxial fatique assessment, University of Padova, Department of Mechanical Engineering, 2001

Vulgakov, B.E.(2000), Gears with Improved Characteristics, Mashinostroenie , Moscow

Ulrich Klein (2003), Schwingungsdiagnostiche Beurteilung von Maschinen und Anlagen Oscillation-Diagnostic Evaluation Machines and Lay Close

Wang, I., Howard, I.(2006), Finite Element Analises of high contact ratio spur gears inmesh, vol.127, Journal of Tribology

Wisnner N. Johan (2004), Gearbox Analysis Using Cepstrum Analysis and Comb Liftering, Brüel \& Kjaer,Denmark 


\section{AUTHOR INDEX}

A

Achebo, J. I.

Acko, B.

Agbinya, J.

Agic, D.

Albertini, G.

Alionte, C. G.

Andrlic, B.

Angelastro, A.

Anh, T. V.

Arivazhagan, A.

Aurite, T.

347

Balazikova, M.

Balic, J. 645

Bancila, D.

Bates, I.

549

Beranoagirre, A.

357,367

Berk, P.

337

Biedunkiewicz, W.

099, 117, 227

Bilas, V.

041

Boca, G.D.

Boiangiu, A.

Boiangiu, M.

Boitor, C.

Bolanca, S.

Botezatu, C. P.

Botezatu, C.

Brezocnik, M.

Brezovnik, S.

Brozovic, M.

313

787

445

445

779

509

559

559

645

645

Buchmeister, B.

Budic, $\mathrm{H}$.

019

027,645

497
Buzatu, C.

549

C

Campanelli, S.L.

413

Carutasu, G.

559

Casalino, G.

413

Catana, D.

575

Cazacioc, L.

301

Celar, S.

Cigula, T.

489,535

Cimolin, V.

195

Comaneci, R.

049,321

Comanescu, A. M. 743

Comanescu, D. M.

583,593

Costencu, M.

583,593

Cotet, C. E.

203

679

\section{D}

Dal Maso, U. 413

Dania, W. A. P.

245

De Pandis, M. F.

049,321

Diaconescu, D.

607

Dima, M. A.

617

Dobra, A.

633

Dobrescu, C.

203

Dobrescu, M.

203

Dragoi, G.

709,725

Dragomirescu, C.

709

Duerr, $\mathrm{H}$.

001

Dumitrescu, D. M.

669
E

E. Ares, G. 
F

Fabisiak, B.

Ferreira, L.

129

Filipoiu, I. D. 463

Filipowicz, K. 583,593

Fota, A. 041

Franc, S.

Fratila, A. 549 313 779

G

G.C. Pelaez, L.

463

Galli, M.

Glusac, D. 049,321

Godina, A. 107

Gojo, M.

Golubovic, K.

Grigorescu, S.

Grundler, D.

Grzesiak, D.

Guran, M.

H

Hrubina, K.

471

I

Izvercianu, M.

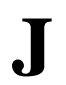

Jadlovska, A.

Jain, P. K.

471

Jaliu, C. 395

Jelic, A.

K

Karuovic, D.

Katalinic, B.

107

Kirinic, V. 607

151

Klanjac, M.

Klicek, B.

Knezevic, N.
Kohout, K.

525

Kremljak, Z. 089

Krolikowski, M.

041

Kumpar, D.

357

L

Lakota, M.

099, 117

Lamikiz, A. 337

Leber, $M$. 027

Lefter, V. 617

Lestan, Z. 645

Lopez de Lacalle, L. N. 337

Lovrencic, S.

289

\section{M}

Macurova, A.

471

Mahovic Poljacek, S.

195

Majercak, J.

Majnaric, I. 471

Mandic, L. 509

Matijevic, M.

Mehta, N. K.

073

259

Mikota, M. 395

Militzer, J. 009, 019

Milkovic, M.

001

Mocan, M. L.

259

Modric, D.

177

Mohamed Mowjoon, M.

367,509

Mrvac, N.

655

Mudnic, E.

$141,151,259$

Muza, R.

535

141

$\mathbf{N}$

Nagyova, A. 219

Neagoe, $\mathrm{M}$. 607

Nica, G. B. 669 
$\mathbf{P}$

Pacaiova, $\mathrm{H}$.

Palcic, I.

Pangica, A.

Panic, N.

Park, H. S.

Pater, L. R.

Pavlovic, I.

Plantak Vukovac, D.

Poenaru, V.

Polajnar, A.

Popa, C. L.

Popa, H. L.

Popescu, B. M.

$\mathbf{R}$

Radosav, D.

Rakun, J.

Risovic, S.

Rolich, T.

Rosu, L.

Rosu, S. M.

Rudolf, C.

Rygallo, A.

107

117

687

697

725

709,725

203

169

\section{$\mathbf{S}$}

Sabau, M.

Salgado, M.

779

Salopek Cubric, I.

Sandru, I. M. D.

Saulescu, R.

Savin, E.

Skala, T.

Skenderi, Z.

Stajnko, D.

463

081

Stanciu, L.

Strgar Kurecic, M
Szuhanek, C.

237

301

027

679

177

Unger, K.

001

Tasic, $\mathrm{T}$.

431

Teich, $\mathrm{T}$.

001

Todorov, R.

753

Tran, N. - A.

001

Turic, M.

489

U

337
Vatau, S.

633

Vickovic, L.

489,535

Vidacek - Hains, V.

289

Vimercati, S.

Vindis, P.

321

Vitalariu, A. M.

Vujica Herzog, N.

Vusic, D.

471

Wessely, E.

Wolny, R. 159,169

Y

Yordanov, R.

753

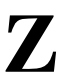

Zezelj, D.

687

Zirra, D.

767

Zjakic, I.

357




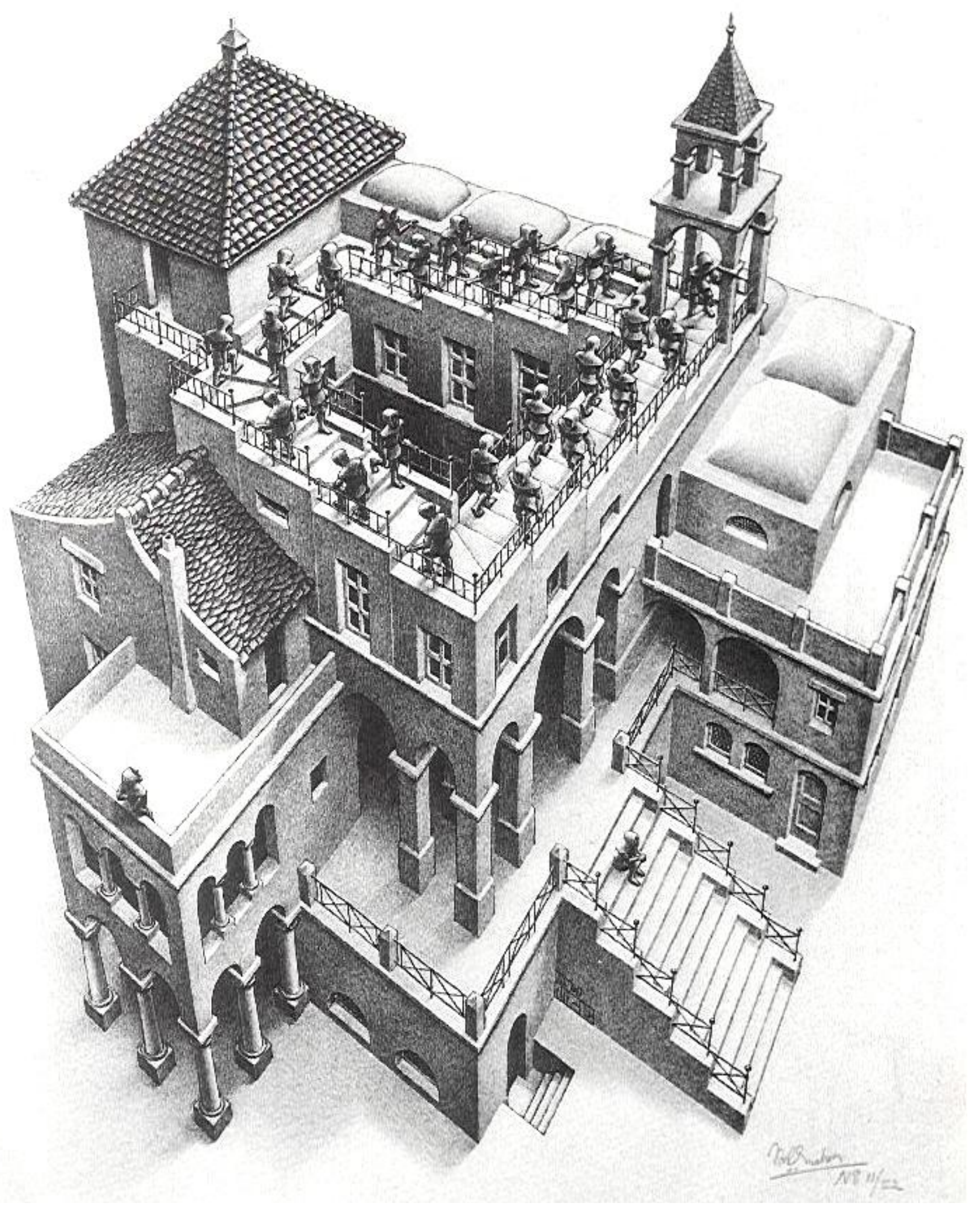




\section{SUBJECT INDEX}

\begin{tabular}{lr} 
A & \\
\hline 3D computer animation & 151 \\
\hline 3D modeling & 141 \\
\hline 8-factor & 525 \\
\hline active sources & 787 \\
\hline advertising media & 019 \\
\hline algorithm & 471,549 \\
\hline aluminum welding flux & 377 \\
\hline analisys & 583 \\
\hline anticipation & 525 \\
\hline application integration & 559 \\
\hline artificial immune systems & 655 \\
\hline assistive technology & 289 \\
\hline automobile assembly lines & 463 \\
\hline automotive component & 057 \\
\hline
\end{tabular}

B

\begin{tabular}{lr}
\hline balanced scorecard & 313 \\
\hline barriers to entry & 617 \\
\hline becoming cycle & 177 \\
\hline behaviour & 525,575 \\
\hline bending & 687 \\
\hline body dimensions & 227 \\
\hline brake disc & 169 \\
\hline bull & 227 \\
\hline business environment & 617 \\
\hline
\end{tabular}

C

\begin{tabular}{ll}
\hline CAD & 583 \\
\hline calibration & 431 \\
\hline call option & 089 \\
\hline cams & 583 \\
\hline capability & 001 \\
\hline case & 089 \\
\hline centrifuge & 445 \\
\hline
\end{tabular}

\begin{tabular}{ll}
\hline children & 107 \\
\hline client-server architecture & 725 \\
\hline clustering & 177 \\
\hline clusters & 177 \\
\hline CNC machine & 169 \\
\hline cognitive & 321 \\
\hline collaborative work & 725 \\
\hline color gamut & 073 \\
\hline color image reproduction & 073 \\
\hline color management & 073 \\
\hline colour difference & 0099 \\
\hline colour & 259 \\
\hline colours & 019 \\
\hline comfort & 081 \\
\hline communication behavior & 669 \\
\hline competitiveness & 617 \\
\hline computer & 559 \\
\hline conceptual design & 607 \\
\hline constructional variables & 159 \\
\hline contestable market & 617 \\
\hline contrast & 259 \\
\hline control & 219 \\
\hline controller & 117 \\
\hline cooling & 593 \\
\hline cooperation & 027 \\
\hline cooperation & 633 \\
\hline correlation & 301 \\
\hline CP and MBTI test & 669 \\
\hline curve & 655 \\
\hline cytokines & \\
\hline
\end{tabular}

\section{D}

deformation 357

\begin{tabular}{ll}
\hline developing devices & 509 \\
\hline
\end{tabular}

device characterization $\quad 073$

device profile $\quad 073$

\begin{tabular}{ll}
\hline DEX-i & 099 \\
\hline
\end{tabular} 


\begin{tabular}{ll}
\hline digital photography & 009 \\
\hline discrete-event simulation & 535 \\
\hline disk cache model & 535 \\
\hline disk simulation & 535 \\
\hline dissimilar materials & 431 \\
\hline drawing & 321 \\
\hline drilling & 337 \\
\hline drought index & 301 \\
\hline dynamic contact angle & 195 \\
\hline
\end{tabular}

$\mathbf{E}$

educational game 107

educational software $\quad 107$

e-learning site virtual enterprise network

725

e-learning

ElectroInk

271

electromagnetic field

509

electrophotography

energy crops

697

509

entrepreneurial activity

entrepreneurship

ERP

evaluation criteria

099

767

evolutionary computation

F

fatigue resistance

743

feature recognition

FEM

fiber

395

financial option

finish machining

finite element analysis

flexibility

FMS $041,159,575$

743

089

395

057

203

679

four-dimensional stakeholder analysis (4DSA) 489

fractals 593

framework 767

free competition friction 687

fuzzy logic 117

\section{G}

Gait Analysis

049

Gamma TiAl

337

gauge block

431

generalized algorithm

607

genetic algorithm

$245,645,697$

genetic

471,549

globalization

313

graphic

141,321

\section{H}

\begin{tabular}{lr}
\hline hazard $\quad 347$ \\
\hline
\end{tabular}

HCI

health 347

heat-pipe

593

helical milling 337

hospitality 497

human immune system

655

hybrid laser welding 413

I

iatrogenic factors 779

image analysis 227

image rendering 141

\begin{tabular}{lr}
\hline improvement & 787 \\
\hline
\end{tabular}

\begin{tabular}{lr}
\hline inks & 367 \\
\hline
\end{tabular}

intelligent systems $\quad 313$

internet $\quad 497$

inventory management $\quad 245$

\begin{tabular}{ll}
\hline ISO speed & 009 \\
\hline
\end{tabular}

job-shop scheduling

645

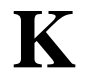

knowledge base 709 
knowledge based system

knowledge management

Koffka

669

language codes

301

large scale circulation

237

laser soldering

M

machines

129

machining features

management

001

219

manufacturing networks

679

manufacturing $\quad 001,129,463,645$

market research 497,617

MATLAB

697

matrix

633

MCM

753

measurement

687

mechanical comparison

431

mental retardation

289

methodology

497

middleware technologies

559

model

471

modeling

471

modification

169

monitoring 129

motor

321

movement problems

151

multicriteria decision analysis $\quad 099$

multi-level

525

multipolar simulation

679

multivariable optimization

Murray-Davies

753

367

$\mathbf{N}$

natural frequencies

nested random model

445

network

numerical simulation
Parkinson's Disease

passive sources

049,321

Peano 787

perception 593

performance measures 259

periodic review system 313

portrait photography 245

post-and-core 009

prediction 743

printing plate 081

printing 195

priority 357

product concept 549

production functions

607

production

001

professional risk assessment

027

progress

709

project

177

PSP 219

put option

049

089

Q

quality

$219,357,787$

queuing delay 535

\section{$\mathbf{R}$}

R\&D

027

real options 089

rehabilitation process

resilient wheels 289

review

041

413




\begin{tabular}{ll}
\hline risks & 347 \\
\hline robots & 633 \\
\hline roll forming & 057 \\
\hline
\end{tabular}

\section{$\mathbf{S}$}

\begin{tabular}{lr}
\hline safety & 347 \\
\hline scene complexity & 141 \\
\hline scheduling & 549 \\
\hline screen element & 357 \\
\hline screen reproduction & 509 \\
\hline security & 203 \\
\hline significance of variable & 159 \\
\hline simulation model & 099 \\
\hline simulation & 463,525 \\
\hline skin colours & 009 \\
\hline SME & 7097 \\
\hline software engineering & 7679 \\
\hline software integration & 151 \\
\hline solid objects & 787 \\
\hline sound & 367 \\
\hline spectrometer & 159 \\
\hline spindle units & 575 \\
\hline spots & 489 \\
\hline stakeholder management strategy & 019 \\
\hline steadfastness & 395 \\
\hline STEP AP203 /214 formats & 377 \\
\hline stoichiometric & 347 \\
\hline stress & 367 \\
\hline substrate & 195 \\
\hline surface free energy & 027 \\
\hline survey & 081 \\
\hline sweating guarded hotplate & 633 \\
\hline synchronization & 177 \\
\hline synthesis & systemics \\
\hline
\end{tabular}

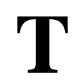

task

347

057

347

549

509

159

099 525

559

151

787
575

019

367

\begin{tabular}{ll}
\hline vibrations & 445 \\
\hline virtual enterprise environment & 669 \\
\hline virtual teams & 725 \\
\hline visualisation & 151 \\
\hline
\end{tabular}

W

weight 227

welding $\quad 575$

wetting 195

wireless mesh network $\quad 655$

Witness

679

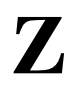

zirconium 